Article

\title{
Telmisartan Exerts Anti-Tumor Effects by Activating Peroxisome Proliferator-Activated Receptor- $\gamma$ in Human Lung Adenocarcinoma A549 Cells
}

\author{
Juan $\mathrm{Li}^{1, \dagger}$, Lin Chen ${ }^{2, \dagger}$, Ping Yu ${ }^{1, *}$, Bin Liu ${ }^{1}$, Jiang Zhu ${ }^{1}$ and Ye Yang ${ }^{1}$ \\ 1 Thoracic Oncology Department, Sichuan Cancer Hospital, Chengdu, Sichuan 610041, China \\ 2 Oncology Department, Sichuan Provincial Hospital and Sichuan Academy of Medical Science, \\ Chengdu, Sichuan 610072, China
}

$\dagger$ These authors contributed equally to this work.

* Author to whom correspondence should be addressed; E-Mail: yuping20101215@163.com; Tel.: +86-013-699-403-884.

Received: 6 January 2014; in revised form: 25 February 2014 / Accepted: 26 February 2014 / Published: 5 March 2014

\begin{abstract}
Telmisartan, a member of the angiotensin II type 1 receptor blockers, is usually used for cardiovascular diseases. Recent studies have showed that telmisartan has the property of PPAR $\gamma$ activation. Meanwhile, PPAR $\gamma$ is essential for tumor proliferation, invasion and metastasis. In this work we explore whether telmisartan could exert antitumor effects through PPAR $\gamma$ activation in A549 cells. MTT and trypan blue exclusion assays were included to determine the survival rates and cell viabilities. RT-PCR and western blotting were used to analyze the expression of ICAM-1, MMP-9 and PPAR $\gamma$. DNA binding activity of PPAR $\gamma$ was evaluated by EMSA. Our data showed that the survival rates and cell viabilities of A549 cells were all reduced by telmisartan in a timeand concentration-dependent manner. Meanwhile, our results also demonstrated that telmisartan dose-dependently inhibited the expression of ICAM-1 and MMP-9. Moreover, the cytotoxic and anti-proliferative effects, ICAM-1 and MMP-9 inhibitive properties of telmisartan were totally blunted by the PPAR $\gamma$ antagonist GW9662. Our findings also showed that the expression of PPAR $\gamma$ was up-regulated by telmisartan in a dose dependent manner. And, the EMSA results also figured out that DNA binding activity of PPAR $\gamma$ was dose-dependently increased by telmisartan. Additionally, our data also revealed that telmisartan-induced PPAR $\gamma$ activation was abrogated by GW9662. Taken together, our
\end{abstract}


results indicated that telmisartan inhibited the expression of ICAM-1 and MMP-9 in A549 cells, very likely through the up-regulation of PPAR $\gamma$ synthesis.

Keywords: telmisartan; A549 cells; lung cancer; peroxisome proliferator-activated receptor- $\gamma \quad$ (PPAR $\gamma)$ intercellular adhesion molecule-1 (ICAM-1); matrix metalloprotease-9 (MMP-9)

\section{Introduction}

Peroxisome proliferator-activated receptor $\gamma(\operatorname{PPAR} \gamma)$, belonging to the peroxisome proliferatorsactivated receptors (PPARs) family, is considered to be essential for modulating multiple physical and pathological processes, including lipid and glucose metabolism, inflammation and fibrosis [1-7]. Additionally, amount of studies also confirmed that PPAR $\gamma$ plays a critical in tumor proliferation and differentiation, apoptosis, invasion, angiogenesis and metastasis [8-12]. Specifically, PPAR $\gamma$ activation was effective in arresting the proliferation of dedifferentiated tumor cells [8-12].

Adhesion molecules are involved in intracellular signaling in several critical pathological processes, including tumor invasion, which is one of the most important features of malignant tumors [13-18]. Among adhesion molecules, intercellular adhesion molecule-1 (ICAM-1), a member of the immunoglobulin supergene family, is an inducible surface glycoprotein. The extracellular domain of ICAM-1 plays a key role in the transendothelial migration of leukocytes from the capillary bed into the tissue [18-20]. Some studies found that ICAM-1 may also promote the tumor cells breaking through the extracellular matrix (ECM) [21,22]. Meanwhile, the studies revealed that overexpression of ICAM-1 was associated with a greater risk of advanced lung cancers (stages III and IV) and more aggressive behaviors in other epithelial-derived cancers, including melanoma, gastric and breast [23]. A wealth of reports demonstrated that PPAR $\gamma$ contributed substantially to the regulation of ICAM-1 in variety of inflammatory conditions [24,25]. Furthermore, Arnold et al. showed that ICAM-1 expression was markedly downregulated by PPAR $\gamma$ activation in A549 cells [26]. Matrix metalloprotease-9 (MMP-9), one of member of the matrix metalloprotease family, is essential for the cancer cell metastasis and migration, which are the major characteristics of malignant tumors and the most important reasons causing death [27-29]. Amount of studies uncovered the role of PPAR $\gamma$ as a central player in the regulation of MMP-9 expression [30-32].

Telmisartan, a member of angiotensin II type 1 receptor blockers (ARBs), is usually used for the treatment of cardiovascular diseases, including hypertension and coronary artery disease (CAD) [33,34]. Recently, several studies indicated that telmisartan and irbesartan have PPAR $\gamma$-activating properties and they have been considered to be the selective PPAR $\gamma$ modulators [35,36]. Taken together, the purpose of this study was to explore the anti-tumor value of telmisartan in lung cancer A549 cells, and the bio-mechanism involved. 


\section{Results and Discussion}

\subsection{Telmisartan Inhibits the Cell Survival Rates and Cell Viabilities of A549 Cells}

To detect the values of telmisartan on the cytotoxicity and proliferation of A549 cells, cells were treated by four different concentrations of telmisartan $(10,25,50$ and $100 \mu \mathrm{M})$ with or without GW9662 $(10 \mu \mathrm{M})$. Our data indicated that both the survival rates and viabilities of A549 cells were reduced by telmisartan in a time- and concentration-dependent manner (Figures 1 and 2). Additionally, Figures 1 and 2 also demonstrated that GW9662 $(10 \mu \mathrm{M})$ abrogated the cytotoxic and anti-proliferative effects of telmisartan $(100 \mu \mathrm{M})$.

Figure 1. Telmisartan inhibits the survival rates of A549 cells. The survival rates of A549 cells was analyzed by MTT assay at specific time points $(0,24,48$, and $72 \mathrm{~h})$ with 4 different concentrations of telmisartan $(10,25,50$ and $100 \mu \mathrm{M})$ or GW9662 $(10 \mu \mathrm{M})$. Quantitative data are presented as mean $\pm \mathrm{SD}(n=4) . * p<0.05$ compared with Control at the corresponding time points. \# $p<0.05$ compared with $10 \mu \mathrm{M}$ telmisartan at the corresponding time points. $\dagger p<0.05$ compared with $25 \mu \mathrm{M}$ telmisartan at the corresponding time points. $\neq p<0.05$ compared with $50 \mu \mathrm{M}$ telmisartan at the corresponding time points.

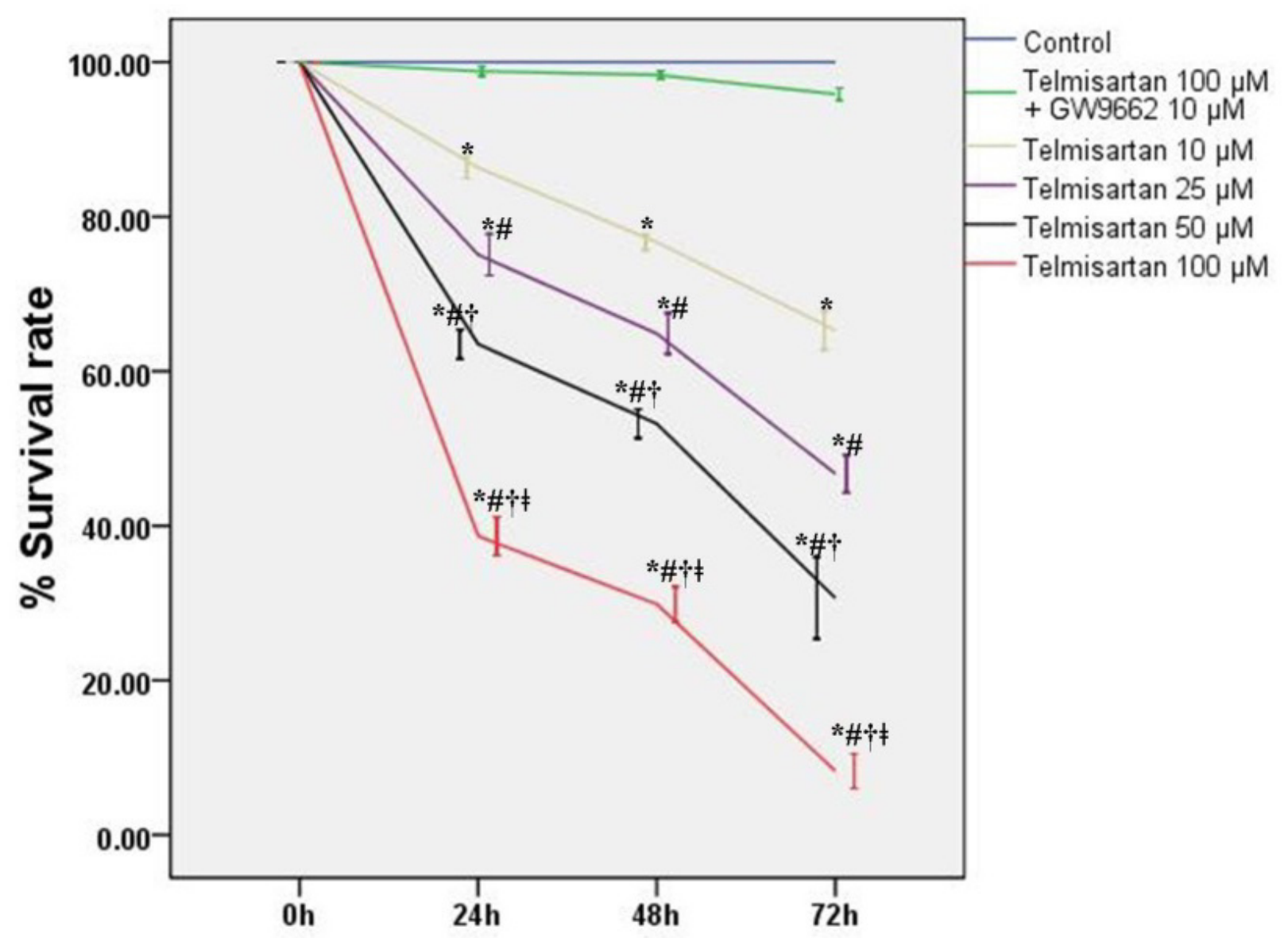


Figure 2. Telmisartan reduces the cell viability of A549 cells. The cell viability of A549 cells was analyzed by trypan blue exclusion assay at specific time points $(0,24,48$, and $72 \mathrm{~h})$ with 4 different concentrations of telmisartan $(10,25,50$ and $100 \mu \mathrm{M})$ or GW9662 $(10 \mu \mathrm{M})$. Quantitative data are presented as mean $\pm \mathrm{SD}(n=4) .{ }^{*} p<0.05$ compared with Control at the corresponding time points. \# $p<0.05$ compared with $10 \mu \mathrm{M}$ telmisartan at the corresponding time points. $\dagger p<0.05$ compared with $25 \mu \mathrm{M}$ telmisartan at the corresponding time points. $\neq p<0.05$ compared with $50 \mu \mathrm{M}$ telmisartan at the corresponding time points.

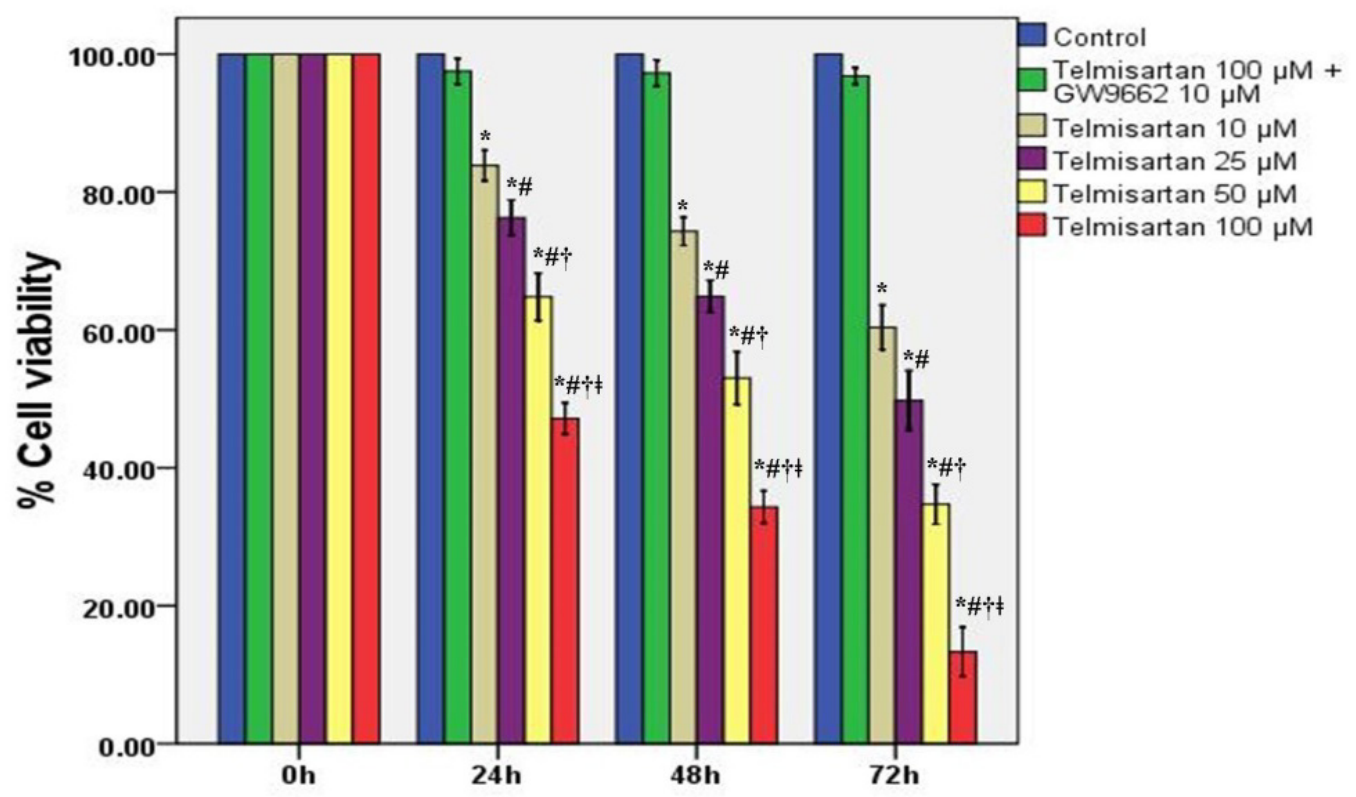

2.2. Telmisartan Dose-Dependently Reduces the $m R N A$ and Protein Expression of ICAM-1 and MMP-9 in A549 Cells

To measure the effect of telmisartan on the mRNA and protein expression of ICAM-1 and MMP-9, RT-PCR and western blotting were used in our study. Figures 3 and 4 showed that telmisartan dose-dependently inhibited the mRNA and protein expression of ICAM-1 and MMP-9. Meanwhile, our data also demonstrated that GW9662 blocked the effect of telmisartan on ICAM-1 and MMP-9 expression.

\subsection{Telmisartan Dose-Dependently Enhances the $m R N A$ and Protein Expression of PPAR in A549 Cells}

RT-PCR and western blotting were performed to measure the mRNA and protein expression of PPAR $\gamma$ in our study. Our results revealed that the mRNA and protein expression of PPAR $\gamma$ was dose-dependently enhanced by telmisartan (Figures 5 and 6). Meanwhile, our data also showed that GW9662 blocked the effect of telmisartan on PPAR $\gamma$ expression.

\subsection{Telmisartan Increases DNA Binding Activity of PPARy in A549 Cells}

EMSA was included to identify PPAR $\gamma$ DNA binding activity in cells. Figure 7 showed that DNA binding activity of PPAR $\gamma$ was dose-dependently increased by telmisartan. Our data also showed that 
GW9662 blunted the effect of telmisartan on PPAR $\gamma$ DNA binding activity. Otherwise, incubation of the nuclear extracts from $100 \mu \mathrm{M}$ telmisartan with monoclonal antibody against PPAR $\gamma$ supershifted the complex to the higher molecular weight position (Lane 1 of Figure 7). This result revealed that the shifted complex contains PPAR $\gamma$.

Figure 3. Telmisartan reduces the mRNA expression of ICAM-1 and MMP-9 in A549 cells. The mRNA expression of ICAM-1 (A) and MMP-9 (B) in A549 cells treated with 4 concentrations of telmisartan $(10,25,50$ and $100 \mu \mathrm{M})$ or GW9662 $(10 \mu \mathrm{M})$ for $48 \mathrm{~h}$ were measured. Quantitative data were presented as mean $\pm \operatorname{SD}(n=4) . * p<0.05$ compared with Control. \# $p<0.05$ compared with $10 \mu \mathrm{M}$ telmisartan. $\dagger p<0.05$ compared with $25 \mu \mathrm{M}$ telmisartan. $\neq p<0.05$ compared with $50 \mu \mathrm{M}$ telmisartan.

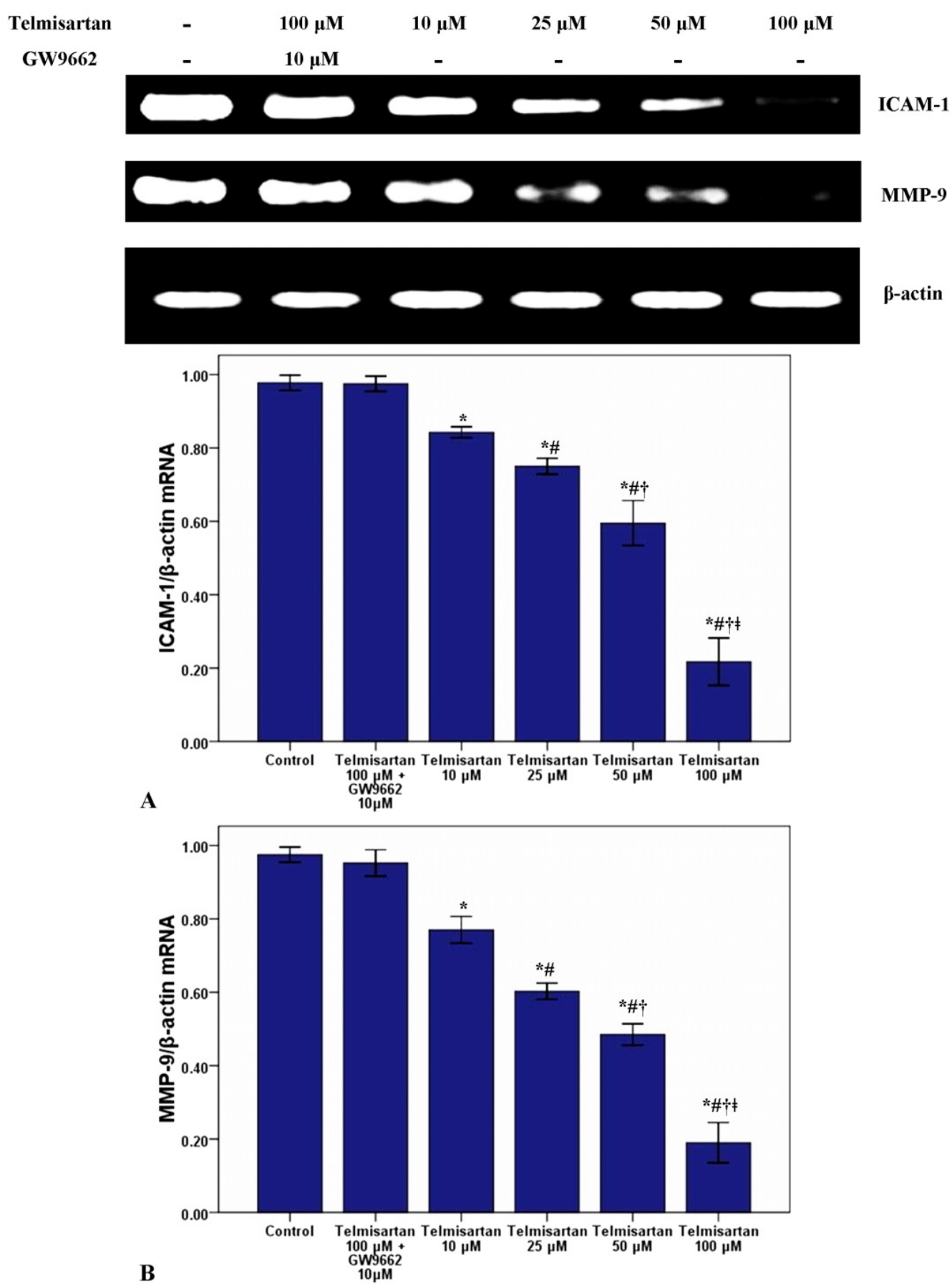


Figure 4. Telmisartan reduces the protein expression of ICAM-1 and MMP-9 in A549 cells. The protein expression of ICAM-1 (A) and MMP-9 (B) in A549 cells treated with 4 concentrations of telmisartan $(10,25,50$ and $100 \mu \mathrm{M})$ or GW9662 $(10 \mu \mathrm{M})$ for $48 \mathrm{~h}$ were measured. Quantitative data were presented as mean $\pm \mathrm{SD}(n=4) .{ }^{*} p<0.05$ compared with Control. \# $p<0.05$ compared with $10 \mu \mathrm{M}$ telmisartan. $\dagger p<0.05$ compared with $25 \mu \mathrm{M}$ telmisartan. $\neq p<0.05$ compared with $50 \mu \mathrm{M}$ telmisartan.

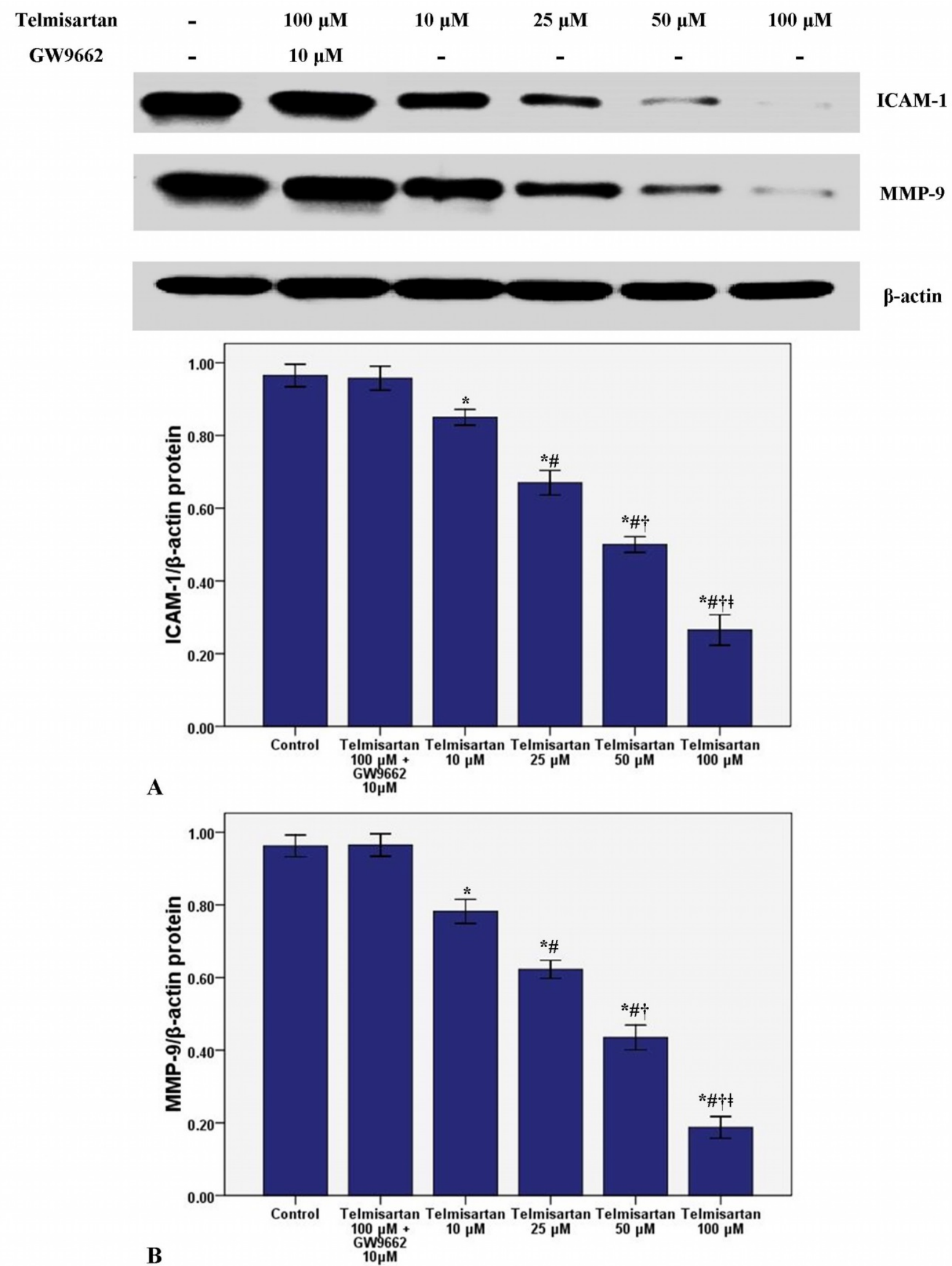


Figure 5. Telmisartan enhances the mRNA expression of PPAR $\gamma$ in A549 cells. The mRNA expression of PPAR $\gamma$ in A549 cells treated with 4 concentrations of telmisartan $(10,25,50$ and $100 \mu \mathrm{M})$ or GW9662 $(10 \mu \mathrm{M})$ for $48 \mathrm{~h}$ were measured. Quantitative data were presented as mean $\pm \mathrm{SD}(n=4)$. ${ }^{*} p<0.05$ compared with Control. $\# p<0.05$ compared with $10 \mu \mathrm{M}$ telmisartan. $\dagger p<0.05$ compared with $25 \mu \mathrm{M}$ telmisartan. $\neq p<0.05$ compared with $50 \mu \mathrm{M}$ telmisartan.

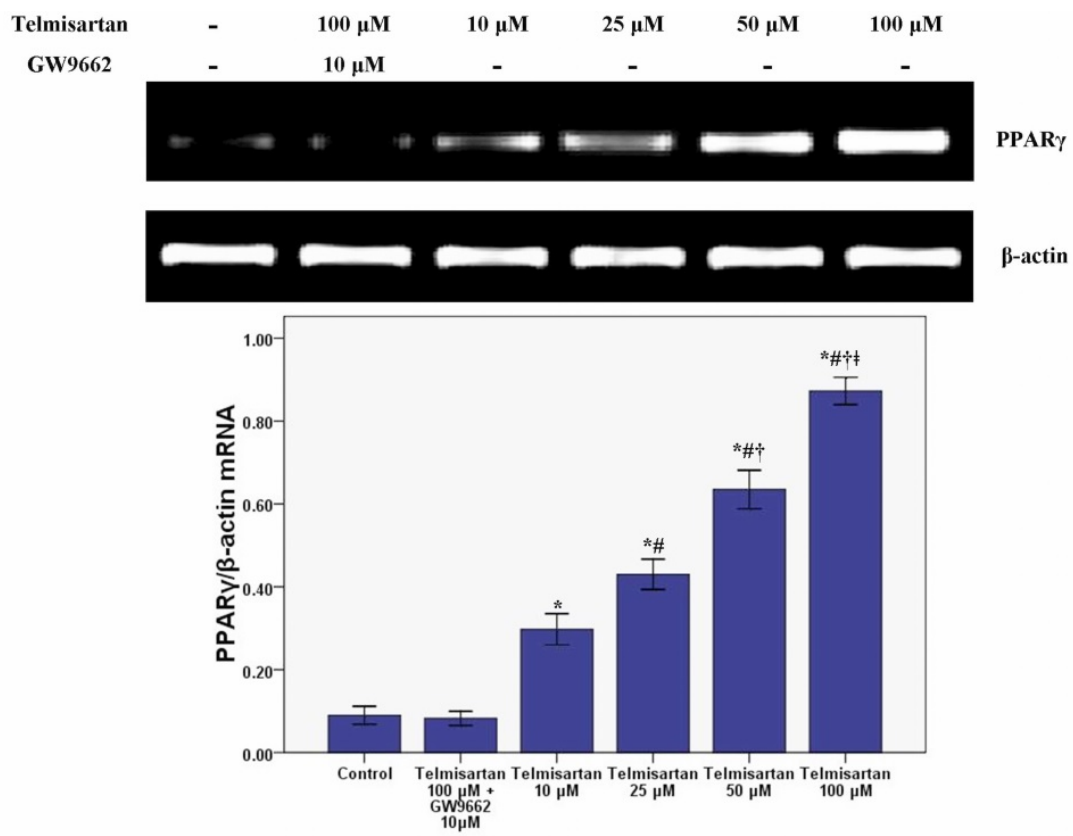

Figure 6. Telmisartan enhances the protein expression of PPAR $\gamma$ in A549 cells. The protein expression of PPAR $\gamma$ in A549 cells treated with 4 concentrations of telmisartan $(10,25,50$ and $100 \mu \mathrm{M})$ or GW9662 $(10 \mu \mathrm{M})$ for $48 \mathrm{~h}$ were measured. Quantitative data were presented as mean $\pm \mathrm{SD}(n=4)$. ${ }^{*} p<0.05$ compared with Control. $\# p<0.05$ compared with $10 \mu \mathrm{M}$ telmisartan. $\dagger p<0.05$ compared with $25 \mu \mathrm{M}$ telmisartan. $\neq p<0.05$ compared with $50 \mu \mathrm{M}$ telmisartan.

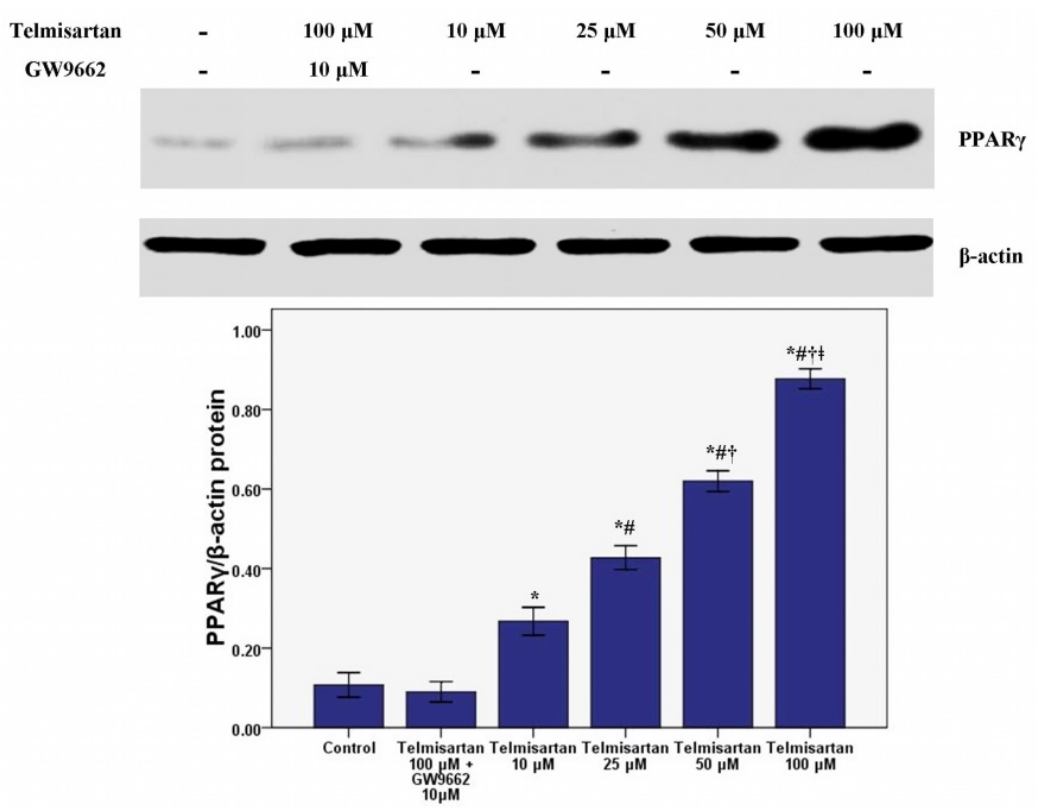


Figure 7. Telmisartan increases DNA binding activity of PPAR $\gamma$ in A549 cells. DNA binding activity of PPAR $\gamma$ in A549 cells treated with 4 concentrations of telmisartan (10, 25, 50 and $100 \mu \mathrm{M})$ or GW9662 $(10 \mu \mathrm{M})$ for $48 \mathrm{~h}$ were examined by EMSA. (1) Nuclear extracts from $100 \mu \mathrm{M}$ telmisartan + oligonucleotide probe + anti-PPAR $\gamma$ antibody; (2) oligonucleotide probe only; (3-9) Nuclear extracts from corresponding group + oligonucleotide probe.

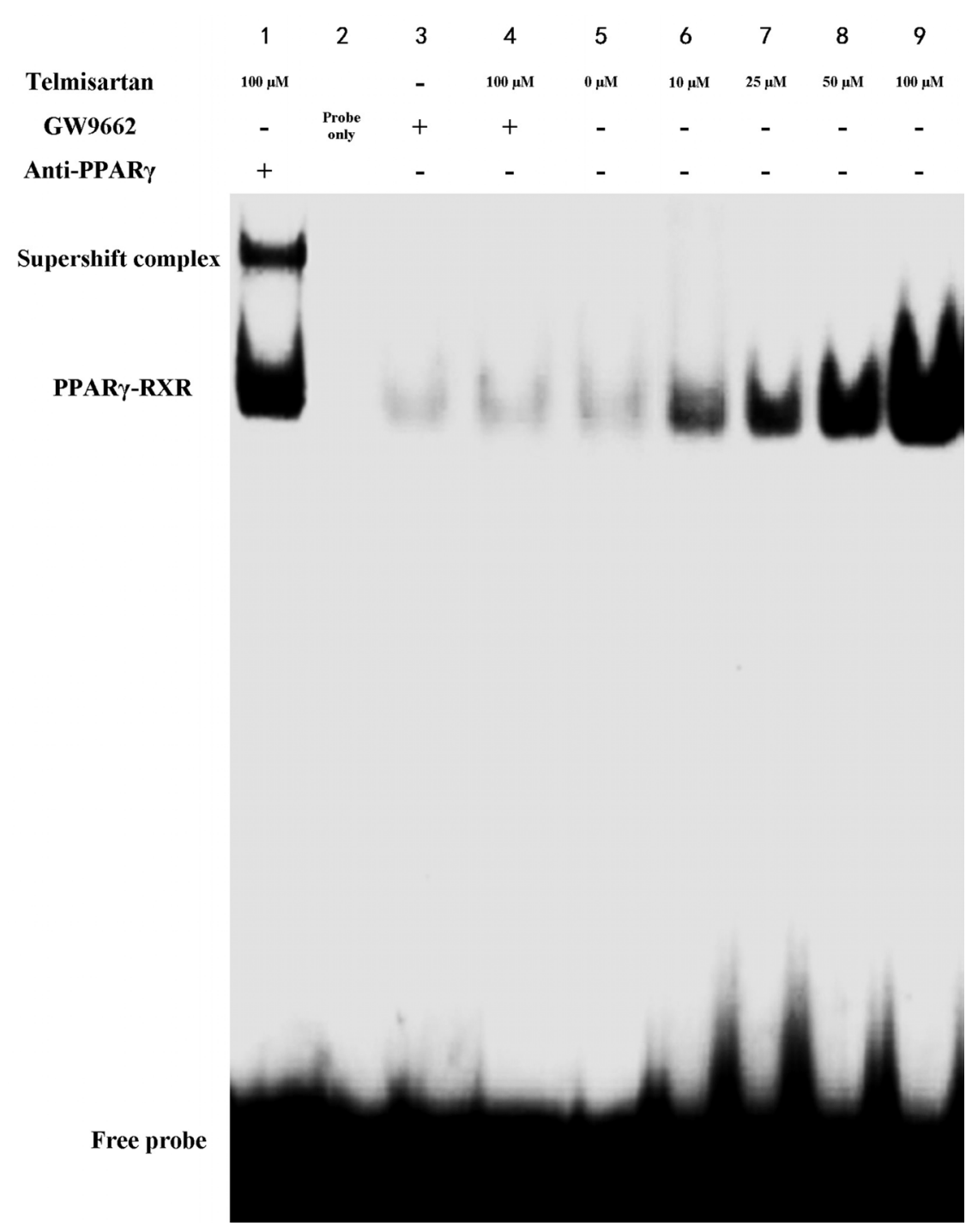

\subsection{Discussion}

In the present study, our results indicated that telmisartan dose-dependently inhibits the cell proliferation and the expression of ICAM-1 and MMP-9 through the up-regulation of PPAR $\gamma$ in human non-small cell lung cancer A549 cells.

Lung cancer has been become the most common cancer globally and the leading cause of cancer deaths in humans. Non-small cell lung cancer (NSCLC) constitutes more than $80 \%$ of primary bronchial lung cancers [29,37]. Despite great progress in surgery, chemotherapy, and radiotherapy, the overall survival rate of patients with NSCLC is still not optimistic [37].

Telmisartan, an angiotensin II type 1 receptor blocker (ARB), is usually used for the treatment of hypertension, coronary artery disease (CAD) and diabetic nephropathy [33-35]. Recently, studies 
confirmed that telmisartan and another ARB, irbesartan, act as a ligand for PPAR $\gamma[35,36]$. Peroxisome proliferator-activated receptors (PPARs) belong to the nuclear hormone receptor family. PPARs consist of three different subtypes, PPAR $\alpha$ (NR1C1), PPAR $\beta / \delta$ (NR1C2), and PPAR $\gamma$ (NR1C3) [1-10]. PPAR $\gamma$ functions as a transcription factor after it heterodimerizes with the retinoid $\mathrm{X}$ receptor (RXR) and binds to the specific response elements, which are termed peroxisome proliferating response elements (PPRE) [1-7]. These PPREs are found in various genes which are involved in lipid metabolism and energy homeostasis, inflammatory regulation, cell proliferation, apoptosis, tumor invasion and metastasis [1-7]. A wealth of studies have showed that PPAR $\gamma$ was expressed in a variety of tumor cells, and the activation of PPAR $\gamma$ by ligands resulted in either suppression of cell proliferation or induction of apoptosis both in vivo and in vitro [8-12]. According to our data, we found that the survival rates and cell viabilities of A549 cells were concentration- and time-dependently inhibited by telmisartan (Figures 1 and 2). Additionally, our findings also revealed that the cytotoxic and anti-proliferative properties of telmisartan were blunted by the PPAR $\gamma$ antagonist GW9662 (Figures 1 and 2). These results indicated that the anti-tumor effect of telmisartan was very likely resulted from PPAR $\gamma$ activation in A549 cells.

Invasion is the one of most critical and fatal characters of malignant tumors. Adhesion of tumor cells to endothelial cells is an essential and initial step of tumor invasion and metastasis [13-17]. Intracellular adhesion molecule-1 (ICAM-1), belonging to the immunoglobulin superfamily, is an inducible 80 - to $110-\mathrm{kDa}$ transmembrane glycoprotein [18-20]. ICAM-1 is traditionally known to be critical for mediating the interaction of leucocytes with endothelial cells in inflammation [18-20]. Meanwhile, some studies also found that many adhesive molecules, including ICAM-1 and vascular adhesion molecule-1 (VCAM-1), can be considered to be crucial for the endothelial adhesion of tumor cells [18-20]. Yu et al. reported that lung cancer (A549) cell invasion could be suppressed by antibody blockade of ICAM-1 or by inhibition the expression of ICAM-1 [21]. Another study also found that ICAM-1 was essential for lung cancer invasion and indicated that ICAM-1 was a biologically based therapy target for lung cancer [22]. Furthermore, it was reported that overexpression of ICAM-1 was associated with a greater risk of advanced lung cancers (stages III and IV) and more aggressive behaviors in other epithelial-derived tumors including melanoma, gastric cancer and breast cancer [21]. Besides, the study also reported that soluble ICAM-1 (sICAM-1) levels had prognostic value for survival and predictive significance for response during chemotherapy in patients with NSCLC [23]. On the other hand, a number of researches confirmed that PPAR $\gamma$ contributed substantially to the regulation of ICAM-1 under a variety of conditions [24-26]. In the current study, our data found that the mRNA and protein expression of ICAM-1 was suppressed by telmisartan in a dose dependent manner. Additionally, the suppressive effect of telmisartan on the expression of ICAM-1 was abrogated by GW9662. These data suggested that ICAM-1 was inhibited by telmisartan, possibly through PPAR $\gamma$ activation in A549 cells.

Intrapulmonary and distant metastases are the principal cause of death from lung cancer. Degradation of the extracellular matrix (ECM), the key process of metastasis, makes tumor cells invade local organs and tissues, intravasate and extravasate blood vessels, promoting metastasis to secondary tumor sites [27-29]. This process is primarily induced by the activity of proteinases secreted by the tumor cells. Matrix metalloproteinases (MMPs), a large family of calcium-dependent zinccontaining endopeptidases, are responsible for the degradation of the ECM, including gelatin, 
collagens, proteoglycan, matrix glycoproteins, and elastins, in the processes of tumor metastasis [27-31]. Research has demonstrated that higher expression of MMPs is often associated with a poor prognosis for the patients with malignant tumors, such as breast cancer, gastric cancer, lung cancer and hepatic cancer $[27,28]$. Meanwhile, according to the data, MMPs have been considered as a promising target for cancer therapy and many synthetic and natural MMP inhibitors (MMPIs) have been found or developed, and have been tested in clinical trials [27]. Among MMPs, MMP-9 plays critical role in tumor cell invasion and metastasis by degradation type IV collagen, one of major components of the ECM [27-29]. Tang et al. found that lung cancer cell invasion and metastasis were enhanced by the up-regulation of MMP-9 in A549 and H1299 cells [38]. Otherwise, some studies also confirmed that the cell proliferation, growth, invasion and metastasis were notably suppressed through inhibition or down-regulation of MMP-9 in lung cancer and other solid cancers [28-30]. Simultaneously, Liu et al. revealed that PPAR $\gamma$ activation was essential for the regulation of MMP-9 in human myeloid leukemia cells [32]. In our study, we found that the mRNA and protein of MMP-9 was dose-dependently inhibited by telmisartan in A549 cells. Furthermore, GW9662 blunted the inhibitive effect of telmisartan on the expression of MMP-9. These data indicated that MMP-9 was inhibited by telmisartan probably via PPAR $\gamma$ activation in A549 cells. Reasonably, the mRNA and protein expression of PPAR $\gamma$ was evaluated in our study. Our data indicated that PPAR $\gamma$ expression was up-regulated by telmisartan in a dose dependent manner in A549 cells. Otherwise, the EMSA result also showed that DNA binding activity of PPAR $\gamma$ was dose-dependently increased by telmisartan in A549 cells. Unsurprisingly, our data also revealed that telmisartan induced PPAR $\gamma$ expression and DNA binding activity in A549 cells were all abrogated by the PPAR $\gamma$ antagonist GW9662. These data indicated that telmisartan was an effective PPAR $\gamma$ modulator, which could up-regulate the expression and DNA binding activity of PPAR $\gamma$, in lung cancer A549 cells.

Therefore, these data indicated that the anti-tumor property of telmisartan possibly results from activation of PPAR $\gamma$ in A549 cells. However, further studies should be carried out to verify the antitumor value of telmisartan in vivo and in clinic experiments. Meanwhile, the involved signal pathways of telmisartan in PPAR $\gamma$ activation should be elucidated in the future as well.

\section{Experimental}

\subsection{Reagents}

A549 cells were purchased from American Type Culture Collection (ATCC, Manassas, VA, USA). Telmisartan was obtained from Sigma Chemical Co (St. Louis, MO, USA). GW9662 (a PPAR $\gamma$ antagonist) was purchased from Cayman Chemicals (St Louis, MO, USA). The MTT assay kit was purchased from Promega (Madison, WI, USA). Trizol reagent was obtained from Invitrogen (Grand Island, NY, USA). Anti- $\beta$-actin (mouse anti-human IgG), anti-PPAR $\gamma$ (mouse anti-human IgG), antiICAM-1 (mouse anti-human IgG), and anti-MMP-9 (mouse anti-human IgG) antibodies were all purchased from Santa Cruz Biotechnology, Inc (Santa Cruz, CA, USA). The Lightshift kit from Pierce (Rockford, IL, USA) was used for EMSA. PPAR consensus oligonucleotides for EMSA were also obtained from Santa Cruz Biotechnology, Inc. 


\subsection{Cell Culture, MTT Assay and Trypan Blue Exclusion}

A549 cells were cultured in RPMI 1640 supplemented with penicillin (100 IU/mL), streptomycin $(100 \mathrm{mg} / \mathrm{mL})$, and $10 \%$ heat-inactivated fetal bovine serum in a humidified atmosphere of $95 \%$ air and $5 \% \mathrm{CO}_{2}$ at $37^{\circ} \mathrm{C}$. A549 cells were then plated at a density of $5 \times 10^{3}$ cells per well in a 96 -well plate. Cells were treated with four different concentrations of telmisartan $(10,25,50$ and $100 \mu \mathrm{M})$ or GW9662 $(10 \mu \mathrm{M})$ in 0.5\% DMSO. Forty-eight hours after interventions, protein and mRNA were extracted from cells. The cytotoxic and anti-proliferative effects of telmisartan were determined by MTT assay and trypan blue exclusion assay, at 4 specified time points (0, 24, 48 and $72 \mathrm{~h})$. For MTT assay, survival rate $(\%)=(\mathrm{OD}$ sample/OD control $) \times 100(\%)$ [37]. For the trypan blue exclusion assay, cell viability $(\%)=($ unstained cells of sample/unstained cells of control $) \times 100(\%)$ [39].

\subsection{RT-PCR (Reverse Transcription-Polymerase Chain Reaction)}

Total RNA was isolated from the A549 cells with Trizol reagent. PCR was performed with a DNA thermal cycler in a $50-\mu \mathrm{L}$ reaction volume, containing $5 \mu \mathrm{L} 10 \times$ Taq Buffer, $4 \mu \mathrm{L}$ of $2.5 \mathrm{mM}$ dNTP, $4 \mu \mathrm{L}$ of $25 \mathrm{mM} \mathrm{MgCl}_{2}, 2 \mu \mathrm{L}$ each forward and backward primers, $0.5 \mu \mathrm{L}$ Taq polymerase, and $2 \mu \mathrm{L}$ cDNA template, for 35 cycles by using a GeneAmp PCR system 9700 (Applied Biosystems, Foster City, CA, USA). The primer sequences were as follows: ICAM-1, (forward) 5'-CCTCACA CTTCACTGTCACCT-3' and (reverse) 5'-CGTGCCGCACTGAACTGGAC-3'; MMP-9, (forward) 5'-ATGAGTTCGGCCACGCGCTGGGCTT-3' and (reverse) 5'-TGCCGGTGATGACACGGAA ACTCAG-3'; PPAR $\gamma$, (forward) 5'-CTATGGAGTTCATGCTTGTG-3' and (reverse) 5'-GTACTGA CATTTATTT-3'; $\beta$-actin, (forward) 5'-CTCCATCCTGGCCTCGCTGT-3' and (reverse) 5'-GCTGT CACCTTCACCGTTCC-3'. The $\beta$-actin housekeeping gene was used as an internal control.

\subsection{Western Blotting}

Western blotting was used to measure the protein content. A549 cells were washed twice with cold

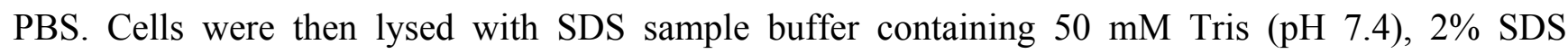
(wt/vol), 5\% 2-mercaptoethanol, and 10\% glycerol. Cell homogenates were centrifuged at 10,000 rpm at $4{ }^{\circ} \mathrm{C}$ for $60 \mathrm{~min}$. The protein concentrations for each sample were measured with a bicinchoninic acid assay kit by using BSA as the standard (Pierce). Protein lysates $(150 \mu \mathrm{g})$ from each sample were subjected to SDS-PAGE on a $10 \%$ acrylamide gel, and the separated proteins were transferred onto a PVDF membrane. After incubation for $1 \mathrm{~h}$ in blocking solution (5\% dry milk in Tris-buffered saline with Tween 20) at room temperature, the membrane was incubated for $24 \mathrm{~h}$ with anti- $\beta$-actin $(1: 1,000)$, anti-ICAM-1 (1:700), anti-MMP-9 (1:800), or anti-PPAR $\gamma(1: 600)$ at $4{ }^{\circ} \mathrm{C}$. The secondary antibody (horseradish peroxidase-conjugated goat anti-mouse immunoglobulin) was added at a 1:10,000 dilution and incubated at room temperature for $1 \mathrm{~h}$. Peroxidase labeling was detected with the enhanced chemoluminescence western blotting detection system (Amersham Pharmacia Biotech, Piscataway, NJ, USA) and analyzed by densitometry. The relative protein level was normalized to $\beta$-actin. 


\subsection{Electrophoretic Mobility Shift Assay (EMSA)}

According to the previous study, EMSA was performed [37]. In brief, nuclear extracts were isolated from A549 cells with Nuclear Extract Kit (Activemotif, Carlsbad, CA, USA). The PPAR consensus oligonucleotides (5'-CAAAACTAGG TCAAAGGTCA-3'/5'-GTTTTGATCCAG TTTCCAGT-3') was used. Binding reactions were performed using a LightShift Chemoluminescent EMSA Kit (Pierce). The reaction mixtures $(10 \mu \mathrm{L})$ containing about $5 \mu \mathrm{g}$ nuclear extracts and 2 pmol of oligonucleotide probe were incubated for $20 \mathrm{~min}$ at RT. Specific binding was confirmed by a 200 -fold excess of unlabeled probe used as a specific competitor. Protein DNA complexes were separated on a $6 \%$ non-denaturing acrylamide gel, transferred to positively charged nylon membranes, and cross-linked using a Stratagene crosslinker (Stratagene, La Jolla, CA, USA). Band shift was visualized with a streptavidin-horseradish peroxidase through chemoluminescent detection.

\subsection{Statistical Analysis}

Statistical analyses were performed with SPSS version 17.0 software. All data in our study were showed as mean $\pm \mathrm{SD}$. A Student's t-test was used to measure significance, where $p<0.05$ was considered to be statistically significant.

\section{Conclusions}

Taken together, our findings confirmed that telmisartan inhibited the expression of ICAM-1 and MMP-9 at the transcriptional level in A549 cells, very likely through the up-regulation of PPAR $\gamma$ synthesis.

\section{Author Contributions}

Ping Yu conceived and designed the experiments and cultivated cells. MTT assay and trypan blue exclusion assay were performed by Juan Li and Lin Chen. Bin Liu, Jiang Zhu and Ye Yang performed RT-PCR and western blot. And EMSA was also performed by Ping Yu and Juan Li. Statistics analysis was performed by Lin Chen. And the manuscript was written by Ping Yu. All authors have read and approved the final version of the manuscript.

\section{Conflicts of Interest}

All authors have declared that no competing interests exist.

\section{References}

1. Rosenson, R.S.; Wright, R.S.; Farkouh, M.; Plutzky, J. Modulating peroxisome proliferator-activated receptors for therapeutic benefit? Biology, clinical experience, and future prospects. Am. Heart J. 2012, 164, 672-680.

2. Choi, J.M.; Bothwell, A.L. The nuclear receptor PPARs as important regulators of T-cell functions and autoimmune diseases. Mol. Cell 2012, 33, 217-222. 
3. Sugawara, A.; Uruno, A.; Matsuda, K.; Saito-Ito, T.; Funato, T.; Saito-Hakoda, A.; Kudo, M.; Ito, S. Effects of PPAR $\gamma$ agonists against vascular and renal dysfunction. Curr. Mol. Pharmacol. 2012, 5, 248-254.

4. Bishop-Bailey, D. PPARs and angiogenesis. Biochem. Soc. Trans. 2011, 39, 1601-1605.

5. Xiao, M.; Zhu, T.; Wang, T.; Wen, F.Q. Diammonium glycyrrhizinate inhibits airway smooth muscle proliferation in a murine model of chronic asthma. Nan Fang. Yi Ke Da Xue Xue Bao 2013, 33, 1416-1420.

6. Deng, Y.L.; Xiong, X.Z.; Cheng, N.S. Organ fibrosis inhibited by blocking transforming growth factor- $\beta$ signaling via peroxisome proliferator-activated receptor $\gamma$ agonists. Hepatobiliary Pancreat. Dis. Int. 2012, 11, 467-478.

7. Yeh, S.L.; Yeh, C.L.; Chan, S.T.; Chuang, C.H. Plasma rich in quercetin metabolites induces G2/M arrest by upregulating PPAR- $\gamma$ expression in human A549 lung cancer cells. Planta Med. 2011, 77, 992-998.

8. Girnun, G.D. The diverse role of the PPAR $\gamma$ coactivator 1 family of transcriptional coactivators in cancer. Semin. Cell Dev. Biol. 2012, 23, 381-388.

9. Peters, J.M.; Shah, Y.M.; Gonzalez, F.J. The role of peroxisome proliferator-activated receptors in carcinogenesis and chemoprevention. Nat. Rev. Cancer 2012, 12, 181-195.

10. Thompson, E.A. PPARgamma physiology and pathology in gastrointestinal epithelial cells. Mol. Cell 2007, 24, 167-176.

11. Wang, D.; Dubois, R.N. Peroxisome proliferator-activated receptors and progression of colorectal cancer. PPAR Res. 2008, 931074.

12. Robbins, G.T.; Nie, D. PPAR gamma, bioactive lipids, and cancer progression. Front. Biosci. 2012, 17, 1816-1834.

13. Yates, C.M.; McGettrick, H.M.; Nash, G.B.; Rainger, G.E. Adhesion of tumor cells to matrices and endothelium. Methods Mol. Biol. 2014, 1070, 57-75.

14. Hung, P.F.; Hong, T.M.; Hsu, Y.C.; Chen, H.Y.; Chang, Y.L.; Wu, C.T.; Chang, G.C.; Jou, Y.S.; Pan, S.H.; Yang, P.C. The motor protein KIF14 inhibits tumor growth and cancer metastasis in lung adenocarcinoma. PLoS One 2013, 8, e61664.

15. Jia, W.; Martin, T.A.; Zhang, G.; Jiang, W.G. Junctional adhesion molecules in cerebral endothelial tight junction and brain metastasis. Anticancer Res. 2013, 33, 2353-2359.

16. Liu, S.Q.; Su, Y.J.; Qin, M.B.; Mao, Y.B.; Huang, J.A.; Tang, G.D. Sphingosine kinase 1 promotes tumor progression and confers malignancy phenotypes of colon cancer by regulating the focal adhesion kinase pathway and adhesion molecules. Int. J. Oncol. 2013, 42, 617-626.

17. Zheng, F.J.; Shi, L.; Yang, J.; Deng, X.H.; Wu, Y.Q.; Yan, X.Q.; Huang, N. Effect of tea polyphenols on the adhesion of highly metastatic human lung carcinoma cell lines to endothelial cells in vitro. Asian Pac. J. Cancer Prev. 2012, 13, 3751-3755.

18. Traub, S.; Nikonova, A.; Carruthers, A.; Dunmore, R.; Vousden, K.A.; Gogsadze, L.; Hao, W.; Zhu, Q.; Bernard, K.; Zhu, J.; et al. An anti-human ICAM-1 antibody inhibits rhinovirus-induced exacerbations of lung inflammation. PLoS Pathog. 2013, 9, e1003520.

19. Zumwalde, N.A.; Domae, E.; Mescher, M.F.; Shimizu, Y. ICAM-1-dependent homotypic aggregates regulate CD8 $\mathrm{T}$ cell effector function and differentiation during $\mathrm{T}$ cell activation. J. Immunol. 2013, 191, 3681-3693. 
20. Dorecka, M.; Siemianowicz, K.; Francuz, T.; Garczorz, W.; Chyra, A.; Klych, A.; Romaniuk, W. Exendin-4 and GLP-1 decreases induced expression of ICAM-1, VCAM-1 and RAGE in human retinal pigment epithelial cells. Pharmacol. Rep. 2013, 65, 884-890.

21. Yu, J.A.; Sadaria, M.R.; Meng, X.; Mitra, S.; Ao, L.; Fullerton, D.A.; Weyant, M.J. Lung cancer cell invasion and expression of intercellular adhesion molecule-1 (ICAM-1) are attenuated by secretory phospholipase $\mathrm{A}_{2}$ inhibition. J. Thorac. Cardiovasc. Surg. 2012, 143, 405-411.

22. Lin, Y.C.; Shun, C.T.; Wu, M.S.; Chen, C.C. A novel anticancer effect of thalidomide: Inhibition of intercellular adhesion molecule-1-mediated cell invasion and metastasis through suppression of nuclear factor-kappaB. Clin. Cancer Res. 2006, 12, 7165-7173.

23. Kotteas, E.A.; Gkiozos, I.; Tsagkouli, S.; Bastas, A.; Ntanos, I.; Saif, M.W.; Syrigos, K.N. Soluble ICAM-1 levels in small-cell lung cancer: Prognostic value for survival and predictive significance for response during chemotherapy. Med. Oncol. 2013, 30, 662.

24. Cianchetti, S.; del Fiorentino, A.; Colognato, R.; di Stefano, R.; Franzoni, F.; Pedrinelli, R. Anti-inflammatory and anti-oxidant properties of telmisartan in cultured human umbilical vein endothelial cells. Atherosclerosis 2008, 198, 22-28.

25. Celiński, K.; Madro, A.; Prozorow-Król, B.; Korolczuk, A.; Cichoz-Lach, H.; Słomka, M.; Korobowicz, E. Rosiglitazone, a peroxisome proliferator-activated receptor gamma (PPARgamma)specific agonist, as a modulator in experimental acute pancreatitis. Med. Sci. Monit. 2009, 15, BR21-BR29.

26. Arnold, R.; Neumann, M.; König, W. Peroxisome proliferator-activated receptor-gamma agonists inhibit respiratory syncytial virus-induced expression of intercellular adhesion molecule-1 in human lung epithelial cells. Immunology 2007, 121, 71-81.

27. Verma, R.P.; Hansch, C. Matrix metalloproteinases (MMPs): Chemical-biological functions and (Q)SARs. Bioorg. Med. Chem. 2007, 15, 2223-2268.

28. Gao, X.H.; Yang, X.Q.; Wang, B.C.; Liu, S.P.; Wang, F.B. Overexpression of twist and matrix metalloproteinase-9 with metastasis and prognosis in gastric cancer. Asian Pac. J. Cancer Prev. 2013, 14, 5055-5060.

29. Ramanujum, R.; Lin, Y.L.; Liu, J.K.; He, S. Regulatory expression of MMP-8/MMP-9 and inhibition of proliferation, migration and invasion in human lung cancer A549 cells in the presence of HGF variants. Kaohsiung J. Med. Sci. 2013, 29, 530-539.

30. Xue, J.; Hua, Y.N.; Xie, M.L.; Gu, Z.L. Aspirin inhibits MMP-9 mRNA expression and release via the PPARalpha/gamma and COX-2/mPGES-1-mediated pathways in macrophages derived from THP-1 cells. Biomed. Pharmacother. 2010, 64, 118-123.

31. Marx, N.; Froehlich, J.; Siam, L.; Ittner, J.; Wierse, G.; Schmidt, A.; Scharnagl, H.; Hombach, V.; Koenig, W. Antidiabetic PPAR gamma-activator rosiglitazone reduces MMP-9 serum levels in type 2 diabetic patients with coronary artery disease. Arterioscler. Thromb. Vasc. Biol. 2003, 23, 283-288.

32. Liu, J.; Lu, H.; Huang, R.; Lin, D.; Wu, X.; Lin, Q.; Wu, X.; Zheng, J.; Pan, X.; Peng, J.; et al. Peroxisome proliferator activated receptor-gamma ligands induced cell growth inhibition and its influence on matrix metalloproteinase activity in human myeloid leukemia cells. Cancer Chemother. Pharmacol. 2005, 56, 400-408. 
33. Chaykovska, L.; Alter, M.L.; von Websky, K.; Hohmann, M.; Tsuprykov, O.; Reichetzeder, C.; Kutil, B.; Kraft, R.; Klein, T.; Hocher, B. Effects of telmisartan and linagliptin when used in combination on blood pressure and oxidative stress in rats with 2-kidney-1-clip hypertension. J. Hypertens. 2013, 31, 2290-2299.

34. Siragusa, M.; Sessa, W.C. Telmisartan exerts pleiotropic effects in endothelial cells and promotes endothelial cell quiescence and survival. Arterioscler. Thromb. Vasc. Biol. 2013, 33, 1852-1860.

35. Chen, Y.; Luo, Q.; Xiong, Z.; Liang, W.; Chen, L.; Xiong, Z. Telmisartan counteracts TGF- $\beta 1$ induced epithelial-to-mesenchymal transition via PPAR- $\gamma$ in human proximal tubule epithelial cells. Int. J. Clin. Exp. Pathol. 2012, 5, 522-529.

36. Shigeto, T.; Yokoyama, Y.; Xin, B.; Mizunuma, H. Peroxisome proliferator-activated receptor alpha and gamma ligands inhibit the growth of human ovarian cancer. Oncol. Rep. 2007, 18, 833-840.

37. Wei, D.; Peng, J.J.; Gao, H.; Li, H.; Li, D.; Tan, Y.; Zhang, T. Digoxin Downregulates NDRG1 and VEGF through the Inhibition of HIF-1 $\alpha$ under Hypoxic Conditions in Human Lung Adenocarcinoma A549 Cells. Int. J. Mol. Sci. 2013, 14, 7273-7285.

38. Tang, Z.P.; Cui, Q.Z.; Dong, Q.Z.; Xu, K.; Wang, E.H. Ataxia-telangiectasia group D complementing gene (ATDC) upregulates matrix metalloproteinase 9 (MMP-9) to promote lung cancer cell invasion by activating ERK and JNK pathways. Tumour Biol. 2013, 34, 2835-2842.

39. Karami, H.; Baradaran, B.; Esfahani, A.; Estiar, M.A.; Naghavi-Behzad, M.; Sakhinia, M.; Sakhinia, E. siRNA-Mediated silencing of survivin inhibits proliferation and enhances etoposide chemosensitivity in acute myeloid leukemia cells. Asian Pac. J. Cancer Prev. 2013, 14, 7719-7724.

Sample Availability: Samples of telmisartan and GW9662 are available from the authors.

(C) 2014 by the authors; licensee MDPI, Basel, Switzerland. This article is an open access article distributed under the terms and conditions of the Creative Commons Attribution license (http://creativecommons.org/licenses/by/3.0/). 